\title{
Association of sputum and blood eosinophil concentrations with clinical measures of COPD severity: an analysis of the SPIROMICS cohort
}

\author{
Annette T Hastie, Fernando J Martinez, Jeffrey L Curtis, Claire M Doerschuk, Nadia N Hansel, Stephanie Christenson, Nirupama Putcha, \\ Victor E Ortega, Xingnan Li, R Graham Barr, Elizabeth E Carretta, DavidJ Couper, Christopher B Cooper, Eric A Hoffman, Richard E Kanner, \\ Eric Kleerup, Wanda K O'Neal, Richard Paine III, Stephen P Peters, Neil E Alexis, Prescott G Woodruff, MeiLan K Han, Deborah A Meyers, \\ Eugene R Bleecker, for the SPIROMICS investigators*
}

Lancet Respir Med 2017; 5: 956-67

Published Online November 13, 2017 http://dx.doi.org/10.1016/ S2213-2600(17)30432-0

See Comment page 913

*Investigators listed in the appendix

Wake Forest School of Medicine, Winston-Salem, NC, USA (Prof A T Hastie PhD, V E Ortega MD,

Prof S P Peters MD); Weill Cornell Medical College of Cornell University, New York, NY, USA (Prof FJ Martinez MD);

VA Ann Arbor Healthcare System, Ann Arbor, MI, USA (Prof J L Curtis MD); University of Michigan, Ann Arbor, MI, USA (Prof) L Curtis,

M K Han MD); University of North Carolina School of Medicine, Chapel Hill, NC, USA (Prof CM Doerschuk MD, W K O'Neal PhD); Johns Hopkins University, Baltimore, MD, USA (N N Hansel MD, N Putcha MD);

University of California

San Francisco, San Francisco,

CA, USA (S Christenson MD Prof P G Woodruff MD);

University of Arizona College of

Medicine, Tucson, AZ, USA

(X Li PhD, Prof D A Meyers PhD, Prof E R Bleecker MD); Columbia

University/Presbyterian

Hospital, New York, NY, USA

(Prof R G Barr MD); University of

North Carolina at Chapel Hill,

Chapel Hill, NC, USA

(E E Carretta MPH,

Prof D J Couper PhD,

Prof N E Alexis PhD); David

Geffen School of Medicine, Los

Angeles, CA, USA

(Prof C B Cooper MD,

E Kleerup MD); University of

lowa, lowa City, IA, USA

(Prof E A Hoffman PhD);

University of Utah Health

Sciences Center, Salt Lake City,

UT, USA (Prof R E Kanner MD,

Prof R Paine III MD);

\section{Summary}

Background Increased concentrations of eosinophils in blood and sputum in chronic obstructive pulmonary disease (COPD) have been associated with increased frequency of exacerbations, reduced lung function, and corticosteroid responsiveness. We aimed to assess whether high eosinophil concentrations in either sputum or blood are associated with a severe COPD phenotype, including greater exacerbation frequency, and whether blood eosinophils are predictive of sputum eosinophils.

Methods We did a multicentre observational study analysing comprehensive baseline data from SPIROMICS in patients with COPD aged 40-80 years who had a smoking history of at least 20 pack-years, recruited from six clinical sites and additional subsites in the USA between Nov 12, 2010, and April 21, 2015. Inclusion criteria for this analysis were SPIROMICS baseline visit data with complete blood cell counts and, in a subset, acceptable sputum counts. We stratified patients on the basis of blood and sputum eosinophil concentrations and compared their demographic characteristics, as well as results from questionnaires, clinical assessments, and quantitative CT (QCT). We also analysed whether blood eosinophil concentrations reliably predicted sputum eosinophil concentrations. This study is registered with ClinicalTrials.gov (NCT01969344).

Findings Of the 2737 patients recruited to SPIROMICS, 2499 patients were smokers and had available blood counts, and so were stratified by mean blood eosinophil count: 1262 patients with low (<200 cells per $\mu \mathrm{L})$ and 1237 with high ( $\geq 200$ cells per $\mu \mathrm{L}$ ) blood eosinophil counts. 827 patients were eligible for stratification by mean sputum eosinophil percentage: 656 with low $(<1 \cdot 25 \%)$ and 171 with high $(\geq 1 \cdot 25 \%)$ sputum eosinophil percentages. The high sputum eosinophil group had significantly lower median $\mathrm{FEV}_{1}$ percentage predicted than the low sputum eosinophil group both before (65.7\% [IQR 51.8-81.3] vs 75.7\% [59.3-90.2], p<0.0001) and after $(77 \cdot 3 \%$ [63.1-88.5] vs 82.9\% [67.8-95.9], $\mathrm{p}=0 \cdot 001$ ) bronchodilation. QCT density measures for emphysema and air trapping were significantly higher in the high sputum eosinophil group than the low sputum eosinophil group. Exacerbations requiring corticosteroids treatment were more common in the high versus low sputum eosinophil group ( $p=0 \cdot 002)$. FEV percentage predicted was significantly different between low and high blood eosinophil groups, but differences were less than those observed between the sputum groups. The high blood eosinophil group had slightly increased airway wall thickness $(0.02 \mathrm{~mm}$ difference, $\mathrm{p}=\mathbf{0} .032)$, higher St George Respiratory Questionnaire symptom scores $(\mathrm{p}=0.037)$, and increased wheezing $(\mathrm{p}=0 \cdot 018)$, but no evidence of an association with COPD exacerbations $(\mathrm{p}=0 \cdot 35)$ or the other indices of COPD severity, such as emphysema measured by CT density, COPD assessment test scores, Body-mass index, airflow Obstruction, Dyspnea, and Exercise index, or Global Initiative for Chronic Obstructive Lung Disease stage. Blood eosinophil counts showed a weak but significant association with sputum eosinophil counts (receiver operating characteristic area under the curve of $0 \cdot 64, \mathrm{p}<0 \cdot 0001$ ), but with a high false-discovery rate of $72 \%$.

Interpretation In a large, well characterised cohort of former and current smoking patients with a broad range of COPD severity, high concentrations of sputum eosinophils were a better biomarker than high concentrations of blood eosinophils to identify a patient subgroup with more severe disease, more frequent exacerbations, and increased emphysema by QCT. Blood eosinophils alone were not a reliable biomarker for COPD severity or exacerbations, or for sputum eosinophils Clinical trials targeting eosinophilic inflammation in COPD should consider assessing sputum eosinophils.

Funding National Institutes of Health, and National Heart, Lung, and Blood Institute.

\section{Introduction}

Airway inflammation in chronic obstructive pulmonary disease (COPD) is characterised by increased concentrations of neutrophils, ${ }^{1}$ macrophages, ${ }^{2}$ proteases, interleukin 6 and 8, and T-helper-1 (Th1) cytokines, whereas airway inflammation in asthma is characterised by increased concentrations of eosinophils and Th2 cytokines. ${ }^{4}$ However, some research has challenged these 


\section{Research in context}

\section{Evidence before this study}

We did a PubMed search for original research reports using the search terms "eosinophils", "sputum", "blood", and "COPD" from April 15, 2014, to May 18, 2017, which yielded 154 articles, of which 32 were reviews. No publication date or language restrictions were used. Addition of "severity" as a search term reduced the publication number to 33 (seven reviews) and addition of "exacerbation" reduced the number to 35 (one review). However, many of these reports have further limitations. Some did not have sputum or blood eosinophil data for comparison, did not specifically focus on the severity of chronic obstructive pulmonary disease (COPD; eg, exacerbations), or were based on small numbers of patients ( $<100$ per group), which limits the power to make conclusions for broader COPD populations. Generally, eosinophils in COPD have been linked to more frequent exacerbations and responsiveness to corticosteroid therapy, suggesting more severe disease. Often, studies are done primarily in populations that have met selection criteria for clinical trials, including the presence of COPD exacerbations. Thus, comparison of blood and sputum eosinophil concentrations for an association with severity of COPD phenotype has not been well studied in a general smoking population with a broad range of COPD severity, nor has possible substitution of blood eosinophils as a biomarker for sputum eosinophils in COPD populations been carefully examined.

presumed differences between the characteristic markers of asthma and COPD.

The ECLIPSE study ${ }^{1}$ reported that in COPD, sputum neutrophil concentrations were weakly associated with lung function and health status, but not associated with exacerbations, emphysema, or systemic inflammation. ECLIPSE reported a mean $1.3 \%$ (SD 2.6) sputum eosinophil concentration in 359 patients with COPD, ${ }^{1}$ but did not observe associations of blood eosinophils with radiological measures of emphysema or with COPD exacerbations and hospital admissions. ECLIPSE reported that concentrations of persistently $2 \%$ or more blood eosinophils (150 cells per $\mu \mathrm{L})$ were associated with evidence of higher $\mathrm{FEV}_{1}$, lower St George Respiratory Questionnaire (SGRQ) score, and modified M edical Research Council score compared with intermittent concentrations or concentrations persistently less than $2 \% .^{5}$ Other COPD studies have reported that increased eosinophils in both blood and sputum are associated with respiratory exacerbations and greater hyperinflation when assessed by quantitative CT (QCT), ${ }^{6,7}$ suggesting that Th2 inflammation $\mathrm{m}$ ight c ontribute t o C OPD p rogression. Furthermore, increased epithelial Th2 signature gene expression has been associated with more severe airflow obstruction in two COPD cohorts. ${ }^{8}$ Eosinophils might therefore be a potential biomarker in COPD because eosinophilia is related to corticosteroid responsiveness. ${ }^{1,9-11}$ In a phase 2 clinical trial, anti-interleukin-5 receptor

\section{Added value of this study}

This study shows that in a large, comprehensively characterised smoking cohort with a broad range of COPD severity, increased sputum eosinophils, but not blood eosinophils alone, had significant associations with multiple measures of COPD severity, including exacerbations, increased emphysema and air trapping, St George Respiratory Questionnaire scores, and Global Initiative for Chronic Obstructive Lung Disease spirometric stage. Blood eosinophils showed weak association with sputum eosinophils and as a single biomarker had few significant associations with COPD severity and exacerbations. However, this study does show that increased blood eosinophils in combination with increased sputum eosinophils show associations with COPD exacerbations and severity.

\section{Implications of all the available evidence}

Increased sputum eosinophils in patients with a broad range of COPD severities identify patients who are more likely to have severe disease and exacerbations. Blood eosinophils as a single biomarker do not accurately predict sputum eosinophils, and do not show any association with disease severity or exacerbations unless observed in combination with increased sputum eosinophils. The findings from this study will be important in the design of therapeutic trials that target eosinophilic inflammation in COPD.

therapy reduced the occurrence of COPD exacerbations in a subgroup of patients with high concentrations of blood and sputum eosinophils. ${ }^{12}$

Establishing disease severity in patients with COPD is complex and involves more than lung function assessments; additional clinical characteristics have been incorporated in successive revisions of the Global Initiative for Chronic Obstructive Lung Disease (GOLD) severity stages. ${ }^{13}$ The current classification includes lung function, symptom scores, and exacerbation frequency. Thus, the severity of COPD is dependent on multiple characteristics, and eosinophilic inflammation might contribute.

Previous reports suggest that blood eosinophil counts might be a useful surrogate measure of airway eosinophils in COPD, ${ }^{11,14}$ although blood eosinophils appear to correlate poorly with sputum eosinophils in asthma, ${ }^{15,16}$ and do not distinguish between populations who are asthma dominant, COPD dominant, or those who have asthma-COPD overlap. ${ }^{17}$ However, larger studies of comprehensively phenotyped patients with COPD often do not have robust sputum eosinophil data either because sputum induction was not done or sputum induction cohorts were small. ${ }^{18-21}$ Thus, whether or not peripheral eosinophils do accurately predict airway eosinophils is unknown.

We investigated the hypotheses that high concentrations of blood and sputum eosinophils in patients with a history and Department of Veteran Affairs Medical Center, Salt Lake City, UT, USA (Prof R Paine III)

Correspondence to: Prof Annette T Hastie, Center for Genomics and Personalized Medicine Research, Wake Forest School of Medicine, Winston-Salem, NC 27157, USA ahastie@wakehealth.edu See Online for appendix 
of tobacco use are associated with a more severe COPD phenotype, identified by diminished lung function, QCT measurements of emphysema or air-trapping, clinical COPD characteristics, and exacerbations. We also investigated relationships between blood and sputum eosinophils to establish whether blood eosinophil concentrations reliably predicted sputum eosinophil concentrations. Measuring blood eosinophils is an easier and less expensive option than sputum induction in a clinical setting. Thus, an ability to predict sputum eosinophils accurately from blood eosinophil concentrations would be useful for clinical studies and patient care. These hypotheses were assessed in the comprehensively characterised SPIROMICS cohort. ${ }^{22}$ A portion of these studies were presented as an abstract at the 2016 American Thoracic Society meeting. ${ }^{23}$

\section{Methods}

\section{Study design and patients}

We did a multicentre observational study of baseline data of the Subpopulations and Intermediate Outcome Measures in COPD Study (SPIROMICS) cohort. Individuals aged 40-80 years with current or former history of tobacco use ( $\geq 20$ pack-years) were enrolled in SPIROMICS at six clinical sites and additional subsites in the USA. ${ }^{22} 2737$ patients were recruited to the SPIROMICS cohort between Nov 12, 2010, and April 21, 2015. Inclusion criteria for this analysis were SPIROMICS baseline visit data with complete blood cell counts and, in a subset, acceptable sputum counts. The cohort included specific groups of smokers with preserved lung function (31\%), GOLD stages 1 and 2 (41\%), or GOLD stages 3 and 4 (21\%), and a control group of non-smokers (7\%). COPD was defined in long-term smokers as a post-bronchodilator $\mathrm{FEV}_{1}$ :forced vital capacity $(\mathrm{FVC}$ ) ratio of less than $0 \cdot 7$. All SPIROMICS participants had extensive baseline phenotypic characterisation as follows: lung function assessment before and after bronchodilation with salbutamol and ipratropium; CT total lung capacity (TLC) and residual volume measurements using QCT indicators for emphysema (\% voxels less than -950 Hounsfield Units $[\mathrm{HU}])$ at TLC and air trapping (\% voxels less than -856 HU) at residual volume; airway metrics (VIDA Diagnostics, Coralville, IA, USA) ${ }^{24}$ and parametric response mapping (PRM) for functional small airways disease; ${ }^{25}$ collection of blood (for DNA, RNA, plasma, sera, IgE, and complete blood cell counts), urine (for cotinine and nicotine metabolites, proline-glycine-proline, and others as requested), 6-min walk distance, GOLD stage, Body-mass index, airflow Obstruction, Dyspnea, and Exercise (BODE) index, COPD assessment test (CAT) score, SGRQ, and medical history questionnaires; and records of numbers of exacerbations (from previous year), hospital admissions, respiratory exposures to vapours, gases, or fumes, and medications. ${ }^{22}$ Sputum was induced in a subset of the SPIROMICS patients, which was based on those who were capable of sputum induction and produced a sufficient

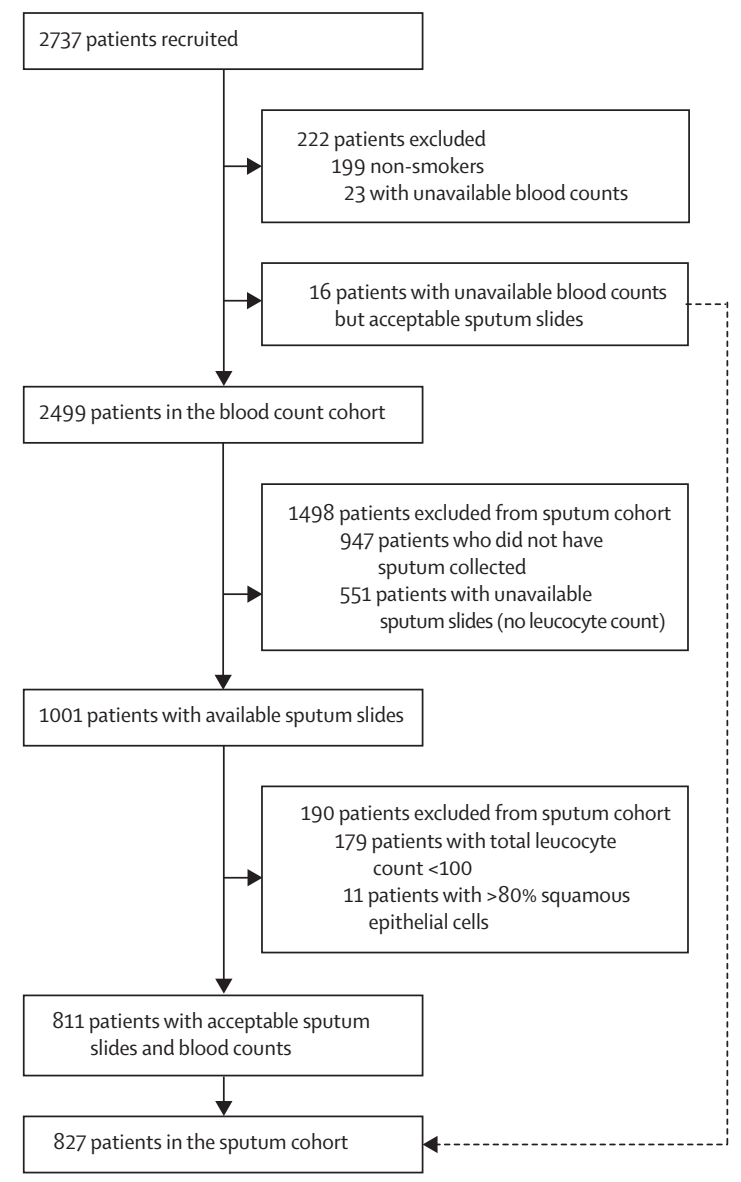

Figure 1: Patient flow diagram

All never-smokers were excluded. Reasons for the reduced number of sputum slide samples available for analysis were as follows: no sputum produced upon completion of induction; no sputum processing form entered; removal of aliquots for mucus analysis and microbiome before processing leaving too little remaining sample for cytospin slide preparation; slides not sent to central slide-reading centre; and slide counts that were deemed unacceptable (leucocyte cell count $<100$ or $>80 \%$ squamous epithelial cells). 16 patients with acceptable sputum differential counts but without blood counts were added to those with both acceptable sputum counts and blood counts to form the sputum cohort.

sample (appendix p 23). Individuals with a primary asthma diagnosis were excluded, but all participants were asked if they had ever had a health-care professional say that they had asthma (previous asthma label). Information on the selection of stratification cutoffs, reproducibility, and other details are provided in the appendix (pp 2-5).

In the SPIROMICS study, patients with postbronchodilator $\mathrm{FEV}_{1}$ percentage predicted of $35 \%$ or more were eligible for sputum induction with saline solutions, and nebulised for three 7-min intervals each. Expectorated sputum samples were processed (appendix pp 3-4) and cytospin slides were read by the central reading centre at University of North Carolina (Chapel Hill, NC, USA). Other exclusion criteria were total leucocyte count of 100 or less, or more than $80 \%$ squamous epithelial cells. Patients 


\begin{tabular}{|c|c|c|c|c|c|c|}
\hline & $\begin{array}{l}\text { Blood eosinophils }<200 \\
\text { cells per } \mu L(n=1262)\end{array}$ & $\begin{array}{l}\text { Blood eosinophils } \\
\geq 200 \text { cells per } \mu \mathrm{L} \\
(\mathrm{n}=1237)\end{array}$ & $p$ value* & $\begin{array}{l}\text { Sputum eosinophils } \\
<1 \cdot 25 \%(n=656)\end{array}$ & $\begin{array}{l}\text { Sputum eosinophils } \\
\geq 1 \cdot 25 \%(n=171)\end{array}$ & p value* \\
\hline Age, years & $65(56-70)$ & $65(59-71)$ & 0.001 & $65(57-71)$ & $64(57-71)$ & 0.87 \\
\hline Sex & & & $<0.0001$ & & & 0.99 \\
\hline Male & $631(50 \%)$ & $730(59 \%)$ & .. & $377(57 \%)$ & $99(58 \%)$ & .. \\
\hline Female & $631(50 \%)$ & $507(41 \%)$ & .. & $279(43 \%)$ & $72(42 \%)$ &.. \\
\hline Race & & & $<0.0001$ & & & 0.90 \\
\hline White & $934(74 \%)$ & $1004(81 \%)$ & .. & $511(78 \%)$ & $132(77 \%)$ & .. \\
\hline Black & $285(23 \%)$ & $173(14 \%)$ & .. & $110(17 \%)$ & $29(17 \%)$ & .. \\
\hline Other & $43(3 \%)$ & $60(5 \%)$ & .. & $35(5 \%)$ & $10(6 \%)$ & .. \\
\hline Body-mass index & $26 \cdot 8(23 \cdot 7-30 \cdot 9)$ & $28 \cdot 2(24 \cdot 5-32 \cdot 1)$ & $<0.0001$ & $28 \cdot 3(24 \cdot 5-32 \cdot 2)$ & $28 \cdot 1(25 \cdot 2-31 \cdot 7)$ & 0.92 \\
\hline Smoking pack-years & $41(30-60)$ & $45(34-60)$ & 0.008 & $43(32-60)$ & $44(33-60)$ & $0 \cdot 70$ \\
\hline Cigarettes per day & $15(9-20)$ & $15(8-20)$ & 0.97 & $15(10-20)$ & $15(6-20)$ & 0.52 \\
\hline Current smoker & $522(42 \%)$ & $451(37 \%)$ & 0.003 & $293(45 \%)$ & $70(41 \%)$ & 0.39 \\
\hline Inhaled corticosteroids & $404(32 \%)$ & $470(38 \%)$ & 0.002 & $169(26 \%)$ & $66(39 \%)$ & 0.002 \\
\hline $\lg E_{,}, I U / m L$ & $34(14-93)$ & $49(19-166)$ & $<0.0001$ & $41(16-104)$ & $56(15-203)$ & $0 \cdot 32$ \\
\hline Sputum eosinophils, \% & $0.23(0.00-0.76)$ & $0.65(0.12-2 \cdot 42)$ & $<0.0001$ &.. &.. & .. \\
\hline $\begin{array}{l}\text { Blood eosinophils, cells per } \\
\mu \mathrm{L}\end{array}$ &.. &.. & .. & $150(100-200)$ & $230(160-350)$ & $<0.0001$ \\
\hline Previous asthma & $249(20 \%)$ & $255(21 \%)$ & $0 \cdot 48$ & $122(19 \%)$ & $48(29 \%)$ & 0.003 \\
\hline Childhood asthma & $97(8 \%)$ & $118(10 \%)$ & $0 \cdot 10$ & $52(8 \%)$ & $20(12 \%)$ & 0.07 \\
\hline
\end{tabular}

Data are median (IQR) or $\mathrm{n}(\%)$. *Mann-Whitney rank sum test for continuous variables, $\chi^{2}$ for categorical variables.

Table 1: Demographics for patients stratified by mean blood or sputum eosinophils

\begin{tabular}{|c|c|c|c|c|c|c|}
\hline & $\begin{array}{l}\text { Blood eosinophils } \\
<200 \text { cells per } \mu \mathrm{L} \\
(\mathrm{n}=1262)\end{array}$ & $\begin{array}{l}\text { Blood eosinophils } \\
\geq 200 \text { cells per } \mu \mathrm{L} \\
(\mathrm{n}=1237)\end{array}$ & p value* & $\begin{array}{l}\text { Sputum eosinophils } \\
<1.25 \%(\mathrm{n}=656)\end{array}$ & $\begin{array}{l}\text { Sputum eosinophils } \\
\geq 1 \cdot 25 \%(\mathrm{n}=171)\end{array}$ & p value* \\
\hline \multicolumn{7}{|c|}{ Lung function before bronchodilator } \\
\hline $\mathrm{FEV}_{1}, \mathrm{~L}$ & $1 \cdot 86(1 \cdot 22-2 \cdot 54)$ & $1.81(1 \cdot 16-2 \cdot 55)$ & 0.38 & $2 \cdot 15(1 \cdot 57-2 \cdot 77)$ & $1 \cdot 83(1 \cdot 38-2 \cdot 32)$ & $<0.0001$ \\
\hline $\mathrm{FEV}_{1}$ percentage predicted & $70 \cdot 5(46 \cdot 6-88 \cdot 2)$ & $66 \cdot 3(42 \cdot 0-85 \cdot 6)$ & 0.006 & $75 \cdot 7(59 \cdot 3-90 \cdot 2)$ & $65 \cdot 7(51 \cdot 8-81 \cdot 3)$ & $<0.0001$ \\
\hline FVC percentage predicted & $87 \cdot 2(74 \cdot 1-99 \cdot 3)$ & $84 \cdot 4(70 \cdot 1-96 \cdot 7)$ & 0.0002 & $90 \cdot 9(78 \cdot 9-100 \cdot 0)$ & $87 \cdot 1(76 \cdot 9-97 \cdot 1)$ & 0.06 \\
\hline $\mathrm{FEV}_{1}: \mathrm{FVC}$ & $0.64(0.49-0.73)$ & $0.61(0.47-0.72)$ & 0.016 & $0.66(0.58-0.74)$ & $0.61(0.52-0.69)$ & $<0.0001$ \\
\hline \multicolumn{7}{|c|}{ Lung function after bronchodilator } \\
\hline $\mathrm{FEV}_{1}, \mathrm{~L}$ & $2.05(1.43-2 \cdot 72)$ & $2.03(1.39-2.75)$ & 0.62 & $2 \cdot 34(1 \cdot 78-2 \cdot 59)$ & $2 \cdot 11(1 \cdot 69-2 \cdot 59)$ & 0.003 \\
\hline $\mathrm{FEV}_{1}$ percentage predicted & $77 \cdot 7(53 \cdot 9-94 \cdot 4)$ & $74 \cdot 2(51 \cdot 6-91 \cdot 4)$ & 0.008 & $82 \cdot 9(67 \cdot 8-95 \cdot 9)$ & $77 \cdot 3(63 \cdot 1-88 \cdot 5)$ & 0.001 \\
\hline FVC percentage predicted & $92 \cdot 9(81 \cdot 3-103 \cdot 8)$ & $90 \cdot 5(78 \cdot 8-101 \cdot 6)$ & 0.001 & $94 \cdot 5(85 \cdot 1-105 \cdot 2)$ & $94 \cdot 2(85 \cdot 9-104 \cdot 1)$ & 0.84 \\
\hline $\mathrm{FEV}_{1}: \mathrm{FVC}$ & $0.66(0.50-0.76)$ & $0.63(0.49-0.74)$ & 0.004 & $0.68(0.59-0.76)$ & $0.64(0.55-0.72)$ & 0.0002 \\
\hline Percentage $\mathrm{FEV}_{1}$ reversibility & $9 \cdot 3(4 \cdot 2-17 \cdot 7)$ & $9 \cdot 8(4 \cdot 5-19 \cdot 0)$ & 0.46 & $8 \cdot 0(3 \cdot 7-15 \cdot 4)$ & $11 \cdot 6(6 \cdot 0-21 \cdot 8)$ & $<0.0001$ \\
\hline
\end{tabular}

Data are median (IQR). FVC=forced vital capacity. *Mann-Whitney rank sum test for continuous variables.

Table 2: Lung function for patients stratified by mean blood or sputum eosinophils

with no sputum collected or no slides prepared were also excluded from sputum analyses.

All SPIROMICS sites that enrolled patients obtained informed consent from patients and were approved by their institutional review boards.

\section{Statistical analysis}

Measures not meeting the Kolmogorov-Smirnov test for normal distribution were transformed by log, or square root values. Continuous variables were tested by parametric or non-parametric tests (appendix p 5; SAS version 9.2 and Sigmastat version 12.5 ). We analysed categorical variables with $\chi^{2}$ or Fisher's exact tests. Correlations were examined by Pearson correlation coefficient or linear regression. Receiver operating characteristic (ROC) analysis was done for blood eosinophil prediction of sputum eosinophils. We examined the false discovery rate, which was the number of false positives divided by false positives plus true positives. We did a classification tree analysis of sputum and blood eosinophils to model exacerbations using Rpart routines in $\mathrm{R}$ software package. $\mathrm{p}$ values of less 


\begin{tabular}{|c|c|c|c|c|c|c|}
\hline & $\begin{array}{l}\text { Blood eosinophils } \\
<200 \text { cells per } \mu \mathrm{L} \\
(\mathrm{n}=1262)\end{array}$ & $\begin{array}{l}\text { Blood eosinophils } \\
\geq 200 \text { cells per } \mu \mathrm{L} \\
(\mathrm{n}=1237)\end{array}$ & p value* & $\begin{array}{l}\text { Sputum eosinophils } \\
<1.25 \%(n=656)\end{array}$ & $\begin{array}{l}\text { Sputum eosinophils } \\
\geq 1 \cdot 25 \%(n=171)\end{array}$ & p value* \\
\hline $\begin{array}{l}\text { TLC left upper lobe, } \\
\text { percentage <-950 HU }\end{array}$ & 3.22 (1.11 to 1.84$)$ & $3.77(1.20$ to 1.50$)$ & 0.66 & 2.24 (0.89 to $5 \cdot 74)$ & 2.88 (1.09 to 7.65$)$ & 0.046 \\
\hline $\begin{array}{l}\text { TLC right upper lobe, } \\
\text { percentage }<-950 \mathrm{HU}\end{array}$ & $2.78(0.72$ to 12.97$)$ & $2.87(0.73$ to 11.96$)$ & 0.76 & $1.73(0.59$ to 5.58$)$ & $2.43(0.91$ to 7.24$)$ & 0.011 \\
\hline $\begin{array}{l}\text { TLC left lower lobe, } \\
\text { percentage <-950 HU }\end{array}$ & 2.09 (0.81 to 7.09$)$ & $2.42(0.88$ to 7.50$)$ & 0.23 & $1.60(0.72$ to 3.78$)$ & 1.98 (0.76 to 5.32$)$ & 0.044 \\
\hline $\begin{array}{l}\text { Residual volume both lungs, } \\
\text { percentage }<-856 \mathrm{HU}\end{array}$ & $17 \cdot 4(6 \cdot 71$ to $39 \cdot 38)$ & 18.91 (7.39 to $40 \cdot 71)$ & 0.28 & $12 \cdot 52(5 \cdot 34$ to $25 \cdot 27)$ & $17 \cdot 20$ ( 8.57 to 33.13$)$ & 0.001 \\
\hline $\begin{array}{l}\text { PRM for functional small } \\
\text { airways disease, } \%\end{array}$ & 14 (4 to 33 ) & 15 (4 to 34 ) & $0 \cdot 21$ & 9 (3 to 22$)$ & 13 (6 to 26$)$ & 0.011 \\
\hline $\begin{array}{l}\text { Wall thickness of apical } \\
\text { right upper lobe, mm }\end{array}$ & 1.26 (1.15 to 1.37$)$ & 1.28 (1.16 to 1.39$)$ & 0.032 & 1.28 (1.18 to 1.38$)$ & $1.29(1.19$ to 1.42$)$ & 0.08 \\
\hline Taper ratio of apical & $0.04(-0.01$ to 0.09$)$ & $0.04(-0.01$ to 0.09$)$ & 0.87 & $0.03(-0.01$ to 0.08$)$ & $0.03(-0.01$ to 0.08$)$ & 0.93 \\
\hline
\end{tabular}

right upper lobe

Data are median (IQR). TLC=total lung capacity. HU=Hounsfield units. PRM=parametric response mapping. *Mann-Whitney rank sum test for continuous variables

Table 3: Imaging parameters for patients stratified by mean blood or sputum eosinophils

than 0.05 were considered significant. ${ }^{26}$ An observational studies monitoring board meets annually to review the study and make recommendations to the National Heart, Lung, and Blood Institute. The SPIROMICS study is registered with ClinicalTrials.gov (NCT01969344).

\section{Role of the funding source}

The funder had no role in the study design, data collection, analysis, interpretation, or writing of this report. The corresponding author had full access to all data in the study and all coauthors gave final approval for the decision to submit for publication.

\section{Results}

Of the 2737 patients recruited to SPIROMICS, 2499 patients were smokers and had available blood counts (figure 1). Mean blood eosinophil count in these 2499 patients was 200 cells per $\mu \mathrm{L}$ (SD 240; median 190 cells per $\mu \mathrm{L}$ [IQR 100-250]; range $0-8300$ cells per $\mu \mathrm{L}$ ), thus, 200 cells per $\mu \mathrm{L}$ was used as the cutoff for analyses. A higher eosinophil cutoff of 300 cells per $\mu \mathrm{L}$ was also examined. The 2499 patients were grouped according to their blood eosinophil count: 1262 patients with low $(<200$ cells per $\mu \mathrm{L})$ and 1237 with high ( $\geq 200$ cells per $\mu \mathrm{L})$ blood eosinophil counts.

Sputum slides were available for 1001 patients (figure 1). 179 patients with differential counts (500-600 total cells) of 100 leucocytes or less in total and 11 patients with $80 \%$ or more squamous epithelia were excluded from the analysis. In the 811 individuals with sputum counts, plus 16 other SPIROMICS patients who had sputum counts but not blood eosinophil counts available (total 827), the mean sputum eosinophil percentage was $1.25 \%$ (SD $4 \cdot 25 \%$; median $0 \cdot 3 \%$ [IQR $0 \cdot 00-0 \cdot 97$ ]; range $0-75 \%$ ), so $1 \cdot 25 \%$ was used as the cutoff for analyses. A higher cutoff of $2 \%$ for sputum eosinophils was also examined. The 827 patients with available sputum counts were grouped according to sputum eosinophil concentrations: 656 with low $(<1.25 \%)$ and 171 with high $(\geq 1 \cdot 25 \%)$ sputum eosinophil counts.

We compared demographic characteristics between patients with high versus low mean blood eosinophil counts and between patients with high versus low mean sputum eosinophil percentages (table 1). Patients with low blood eosinophils $(<200$ cells per $\mu \mathrm{L})$ differed significantly with regard to age, sex, race, body-mass index (BMI), smoking history (pack-years), the proportion who were current smokers, and the proportion who used inhaled corticosteroids from the patients with high blood eosinophil counts $(\geq 200$ cells per $\mu \mathrm{L})$, although differences between the groups were small at less than $10 \%$. Although the proportion of current smokers was smaller in the high eosinophil group, the number of cigarettes smoked each day was similar. Proportions of patients taking five different medications were not significantly different (appendix p 10). Total serum IgE concentrations and percentage sputum eosinophils were significantly higher in the high blood eosinophil group than the low blood eosinophil group, but no significant difference was recorded in the proportions of patients with a previous asthma label or childhood asthma (table 1). The median sputum eosinophil percentage in both groups was lower than the overall sputum eosinophil mean of $1 \cdot 25 \%$.

No significant difference was recorded between patients with low sputum eosinophil counts $(<1 \cdot 25 \%)$ and patients with high sputum eosinophils $(\geq 1 \cdot 25 \%)$ in terms of age, sex, race, BMI, smoking history (pack-years), cigarettes smoked per day, or the proportion who were current smokers. Lymphocyte counts were significantly different between the high and low sputum eosinophil groups (appendix p 11). The high sputum eosinophil group had a significantly greater proportion of patients who had used 


\begin{tabular}{|c|c|c|c|c|c|c|}
\hline & $\begin{array}{l}\text { Blood eosinophils } \\
<200 \text { per } \mu \mathrm{L}(\mathrm{n}=1262)\end{array}$ & $\begin{array}{l}\text { Blood eosinophils } \\
\geq 200 \text { per } \mu \mathrm{L}(\mathrm{n}=1237)\end{array}$ & p value* & $\begin{array}{l}\text { Sputum eosinophils } \\
<1.25 \%(n=656)\end{array}$ & $\begin{array}{l}\text { Sputum eosinophils } \\
\geq 1 \cdot 25 \%(n=171)\end{array}$ & p value ${ }^{*}$ \\
\hline GOLD stage & & & $0.10 \dagger$ & & & $0.001 \dagger$ \\
\hline 0 & $505(40 \%)$ & $425(34 \%)$ & & $295(45 \%)$ & $51(30 \%)$ & \\
\hline 1 & $150(12 \%)$ & $153(12 \%)$ & & $106(16 \%)$ & $31(18 \%)$ & \\
\hline 2 & $323(26 \%)$ & $359(29 \%)$ & & $200(31 \%)$ & $76(44 \%)$ & \\
\hline 3 & $190(15 \%)$ & $200(16 \%)$ & & $47(7 \%)$ & $11(6 \%)$ & \\
\hline 4 & $79(6 \%)$ & $86(7 \%)$ & & $0(0 \%)$ & $1(1 \%)$ & \\
\hline 6-min walk distance, $\mathrm{m}$ & $418(354-482)$ & $410(341-471)$ & 0.12 & $426(372-482)$ & $426(363-478)$ & 0.40 \\
\hline BODE index & $1(0-2)$ & $1(0-2)$ & 0.29 & $0(0-1)$ & $1(0-2)$ & 0.09 \\
\hline COPD score (CAT) & $13(7-20)$ & $13(7-19 \cdot 5)$ & 0.45 & $12(7-19)$ & $13(8-20)$ & 0.18 \\
\hline SGRQ (total) & $31 \cdot 5(14 \cdot 9-48 \cdot 2)$ & $31 \cdot 2(16 \cdot 4-47 \cdot 1)$ & 0.81 & $26 \cdot 2(14 \cdot 0-43 \cdot 6)$ & $31 \cdot 8(17 \cdot 2-47 \cdot 1)$ & 0.05 \\
\hline SGRQ (symptoms) & $45 \cdot 3(22 \cdot 9-66 \cdot 3)$ & $48 \cdot 8(27 \cdot 0-66 \cdot 3)$ & 0.037 & $45 \cdot 2(23 \cdot 5-65 \cdot 1)$ & $53 \cdot 6(34 \cdot 0-69 \cdot 7)$ & 0.004 \\
\hline Wheezing & $741(59 \%)$ & $788(64 \%)$ & 0.018 & $389(60 \%)$ & $116(68 \%)$ & 0.07 \\
\hline
\end{tabular}

Data are median (IQR) or n (\%). GOLD=Global Initiative for Chronic Obstructive Lung Disease. BODE=Body-mass index, airflow Obstruction, Dyspnea, and Exercise. $\mathrm{COPD}=$ chronic obstructive pulmonary disease. $\mathrm{CAT}=\mathrm{COPD}$ assessment test. SGRQ=St George Respiratory Questionnaire. *Mann-Whitney rank sum test for continuous variables or $\chi^{2}$ for categorical variables. †Value for all GOLD stages combined.

Table 4: Clinical characteristics for patients stratified by mean blood or sputum eosinophils

\begin{tabular}{|c|c|c|c|c|c|c|}
\hline & $\begin{array}{l}\text { Blood eosinophils } \\
<200 \text { per } \mu \mathrm{L} \\
(\mathrm{n}=1262)\end{array}$ & $\begin{array}{l}\text { Blood eosinophils } \\
\geq 200 \text { per } \mu \mathrm{L} \\
(\mathrm{n}=1237)\end{array}$ & p value* & $\begin{array}{l}\text { Sputum eosinophils } \\
<1.25 \%(n=656)\end{array}$ & $\begin{array}{l}\text { Sputum eosinophils } \\
\geq 1 \cdot 25 \%(n=171)\end{array}$ & p value* \\
\hline Total & $311(25 \%)$ & $309(25 \%)$ & 0.35 & $125(19 \%)$ & $44(26 \%)$ & 0.05 \\
\hline Requiring health-care use & $294(23 \%)$ & $291(24 \%)$ & 0.36 & $125(19 \%)$ & $43(25 \%)$ & 0.07 \\
\hline Antibiotic treatment & $232(18 \%)$ & $240(19 \%)$ & 0.29 & $92(14 \%)$ & $34(20 \%)$ & 0.09 \\
\hline Corticosteroid treatment & $199(16 \%)$ & $209(17 \%)$ & 0.27 & $66(10 \%)$ & $32(19 \%)$ & 0.002 \\
\hline Any drug treatment & $265(21 \%)$ & $273(22 \%)$ & 0.29 & $105(16 \%)$ & $39(23 \%)$ & 0.033 \\
\hline Severe† & $137(11 \%)$ & $162(13 \%)$ & 0.15 & $52(8 \%)$ & $22(13 \%)$ & 0.044 \\
\hline
\end{tabular}

Data are $n$ (\% positive). ${ }^{*} \chi^{2}$ test. $\dagger$ Exacerbations involving a trip to an emergency department or admission to hospital.

Table 5: Comparison of exacerbations occurring in the previous year for patients stratified by mean blood or sputum eosinophils

inhaled corticosteroids (table 1) and inhaled or nebulised bronchodilators than the low sputum eosinophil group (appendix p 10). The sputum eosinophil groups, unlike the blood eosinophil groups, did not have significantly different I gEc oncentrations. $\mathrm{R}$ egardless, $\mathrm{t}$ he I gE concentrations in the low and high sputum eosinophil groups were similar to those in the low and high blood eosinophil groups. The high sputum eosinophil group had a higher concentration of blood eosinophils than the low sputum eosinophil group (median 230 cells per $\mu \mathrm{L}$ [IQR 160-350] vs 150 cells per $\mu \mathrm{L}$ [100-200], $\mathrm{p}<0 \cdot 0001)$ and a greater proportion of patients reporting a previous asthma label (48 [29\%] vs 122 [19\%], p=0.003). Similar results for blood or sputum eosinophil stratification were obtained with the higher cutoffs of 300 cells per mL blood eosinophils or $2 \%$ sputum eosinophils (appendix p 12).

Lung function assessments showed that the high blood eosinophil group had lower pre-bronchodilator $\mathrm{FEV}_{1}$ percentage predicted than the low blood eosinophil group (median 66.3\% [IQR 42.0-85.6] vs 70.5\% [46.6-88.2], $\mathrm{p}=0.006$; table 2), and a significant difference in po stbronchodilator values was seen $(74 \cdot 2 \%[51 \cdot 6-91 \cdot 4]$ vs 77.7
[53.9-94.4], $p=0.008$; table 2). The high sputum eosinophil group had significantly lower $\mathrm{FEV}_{1}$ percentage predicted versus the low sputum eosinophil group both before $(65.7 \% \quad[51 \cdot 8-81 \cdot 3]$ vs $75 \cdot 7 \% \quad[59 \cdot 3-90 \cdot 2]$, $\mathrm{p}<0.0001)$ and after $(77 \cdot 3 \% \quad[63 \cdot 1-88 \cdot 5]$ vs $82.9 \%$ [67.8-95.9], $p=0 \cdot 001)$ bronchodilation. Because of the safety exclusion of patients with post-bronchodilator $\mathrm{FEV}_{1}$ percentage predicted less than 35\% from sputum induction, fewer patients with GOLD stages 3 and 4 were included in the sputum cohort than in the blood cohort. However, the difference between $\mathrm{FEV}_{1}$ percentage predicted before and after bronchodilation was greater between the sputum eosinophil groups than between the blood eosinophil groups. A significant difference was recorded in reversibility of baseline $\mathrm{FEV}_{1}$ percentage predicted between the high and the low sputum eosinophil groups $(11 \cdot 6[6 \cdot 0-21 \cdot 7]$ vs $8[3 \cdot 7-15 \cdot 4]$, $\mathrm{p}<0 \cdot 0001)$, but no significant difference was observed between the blood eosinophil groups $(\mathrm{p}=0 \cdot 46)$. Similar observations were noted between subgroups stratified by the 300 cells per $\mu \mathrm{L}$ blood eosinophil and $2 \%$ sputum eosinophil cutoffs (appendix p 13). 
QCT imaging showed that indices of emphysema (TLC, \% voxels less than $-950 \mathrm{HU}$ ) and air trapping (residual volume, \% voxels less than $-856 \mathrm{HU})^{24}$ did not differ between the blood eosinophil groups (table 3). By contrast, significantly higher emphysema indices were observed in the high sputum eosinophil group versus the low sputum eosinophil group. Additionally, air trapping (residual volume) and PRM for functional small airways disease $^{25}$ were significantly higher in the high sputum eosinophil group than in the low sputum eosinophil group. A small, $0.02 \mathrm{~mm}$ increase in median airway wall thickness at the prespecified RB1 pathway in the apical segment of the right upper lobe (appendix pp 4-5) was seen in the high versus low blood eosinophil groups $(\mathrm{p}=0.032)$, but no difference was seen between the sputum eosinophil groups $(\mathrm{p}=0 \cdot 08)$. Neither blood nor sputum stratification showed any significant difference in airway tapering (an index of bronchiectasis).

With the higher 300 cells per $\mu \mathrm{L}$ blood eosinophil cutoff, the density measures for emphysema or air trapping were not significantly different between groups; but the RB1 airway wall thickness difference was less significant with the higher cutoff than the difference seen with the 200 cells per $\mu \mathrm{L}$ cutoff $(\mathrm{p}=0.044$ vs $\mathrm{p}=0 \cdot 032$ ). The higher cutoff maintained significant differences between low $(<2 \%)$ and high $(\geq 2 \%)$ sputum eosinophil groups in terms of both emphysema and air trapping indices (appendix p 14).

GOLD stages were significantly different between the high and low sputum eosinophil groups $(\mathrm{p}=0 \cdot 001$; table 4$)$. 295 (45\%) of 656 patients with low sputum eosinophils were GOLD stage 0 versus $51(30 \%)$ of 171 in the high sputum eosinophil group; and 200 (31\%) of 656 were GOLD stage 2 in the low sputum eosinophil group versus $76(44 \%)$ of 171 in the high eosinophil group. No significant difference in GOLD stages was recorded between the low and high blood eosinophil groups $(\mathrm{p}=0 \cdot 10)$. The 6-min walk distance, BODE index, and COPD assessment score were not significantly different in either blood or sputum eosinophil stratifications. The high blood eosinophil group had significantly higher proportion of patients who reported wheezing (788 [64\%] of 1237 patients) than the low blood eosinophil group (741 [59\%] of 1262; table 4). SGRQ symptom score was significantly higher in the high blood eosinophil group than the low blood eosinophil group; and both SGRQ total and symptom scores were significantly higher in the high sputum eosinophil group than the low sputum eosinophil group.

With the higher blood eosinophil cutoff of 300 cells per $\mu \mathrm{L}$, a significant difference in GOLD stages was seen between the high and low groups (appendix p 15). With the higher sputum eosinophil cutoff of $2 \%$, GOLD stages and SGRQ total and symptoms scores remained significantly different between the high and low count groups. BODE index, SGRQ impact, and self-reported wheezing, which were not significantly different with the $1 \cdot 25 \%$ sputum cutoff, were significantly different with the $2 \%$ cutoff.

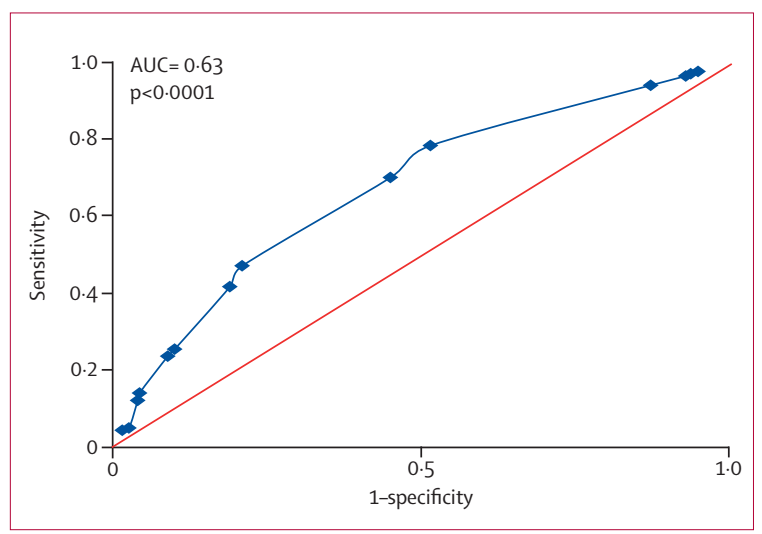

Figure 2: Receiver operating characteristic analysis for blood eosinophil prediction of sputum eosinophils

Blood eosinophils at cutoffs from 50 cells per $\mu \mathrm{L}$ (highest sensitivity) to 500 cells per $\mu \mathrm{L}$ (lowest sensitivity) were examined for correct prediction of sputum eosinophils less than $1.25 \%$ or $1.25 \%$ or more. Maximum sensitivity and specificity were observed at a blood eosinophil cutoff of 150 cells per $\mu \mathrm{L}$. $A \cup C=$ area under the curve.

Exacerbations were compared for associations with blood and sputum eosinophil counts (table 5). Blood eosinophil counts were not significantly associated with any of the different categories of reported exacerbations. By contrast, the high sputum eosinophil group had a higher proportion of patients with exacerbations requiring corticosteroids than the low sputum eosinophil group (32 [19\%] of 171 vs 66 [10\%] of 656; $\mathrm{p}=0 \cdot 002$ ), as well as a higher proportion of patients with exacerbations requiring any drug treatment (39 [23\%] of 171 vs 105 [16\%] of 656; $p=0.033$ ) and with severe exacerbations requiring an emergency department visit (22 [13\%] of 171 vs 52 [8\%] of 656; $\mathrm{p}=0 \cdot 044$ ).

With the higher eosinophil cutoff of 300 cells per $\mu \mathrm{L}$ blood, still no significant differences were seen between the high and low count groups in terms of the proportions of patients with exacerbations; however, the higher $2 \%$ sputum eosinophil cutoff showed significant differences for all categories of COPD exacerbations (appendix p 16).

Tree classification analysis of the association of sputum and blood eosinophil counts with exacerbations selected sputum eosinophils before blood eosinophils, with similar cutoffs to those used in the sputum and blood eosinophil stratification $(1.25 \%$ or $2 \%$ sputum eosinophils and 200 or 300 cells per $\mu \mathrm{L}$ blood eosinophils). The cutoffs were less than $1.9 \%$ or $1.9 \%$ or more for sputum eosinophils and less than 176 cells per $\mu \mathrm{L}$ or 176 cells per $\mu \mathrm{L}$ or more for blood eosinophils. These cutoffs suggest that the $2 \%$ sputum eosinophils and 200 cells per $\mu \mathrm{L}$ blood eosinophils investigated in our study were appropriate (appendix p 23). Exacerbations were recorded in $27(23 \%)$ of 119 patients with sputum eosinophils of more than 1.9\%. By contrast, 65 (9\%) of 692 patients with less than $1.9 \%$ sputum eosinophils had exacerbations (appendix p 23). 
ROC analyses for blood eosinophil prediction of sputum eosinophils showed a weak, although significant, prediction of sputum eosinophils of $1.25 \%$ or more (AUC 0.63, p<0.0001; figure 2); ROC to predict sputum eosinophils of $2 \%$ or more showed similar results (AUC 0.64, p<0.0001; appendix p 24). The highest sensitivity and specificity ( shown b y Y ouden i ndex; appendix $p$ 17) for predicting sputum eosinophils of $1.25 \%$ or more were at 150 cells per $\mu \mathrm{L}$ blood eosinophils; and highest sensitivity and specificity for sputum eosinophils $2 \%$ or more were at 250 cells per $\mu \mathrm{L}$ blood eosinophils. Similar significant A UCs w ere observed at all the assessed adjacent cutoffs, suggesting that the blood eosinophil concentration above which one can confidently and accurately predict increased sputum eosinophils is not sharply defined (appendix p 17 ). Regardless, both associations had very large false discovery rates; $72 \%$ for blood eosinophils of 150 cells per $\mu \mathrm{L}$ or more to predict sputum eosinophils $1.25 \%$ or more (false-negative rate of $22 \%$ ), and $74 \%$ for blood eosinophils of 250 cells per $\mu \mathrm{L}$ or more to predict sputum eosinophils of $2 \%$ or more (false-negative rate of $50 \%)$.

The correlation between sputum eosinophils and blood eosinophils was weak, but significant (figure 3; correlation coefficient $r=0 \cdot 178, \mathrm{p}<0 \cdot 0001) .340(42 \%)$ of 811 patients had discordant blood and sputum eosinophil counts; either high in blood or sputum counts, but not both simultaneously (figure 3). We compared lung function and reported exacerbations for patients in the two discordant and concordant groups (table 6). Both groups with high sputum eosinophils with or without high blood eosinophils had the lowest lung function indicators before bronchodilation. Lung function for the high blood plus low sputum eosinophils group was not significantly different from the group with low blood and low sputum eosinophils (p values not shown). The high blood plus high sputum eosinophil group had a greater proportion of patients with COPD exacerbations than the group with high blood but low sputum eosinophils; exacerbations treated with corticosteroids $(\mathrm{p}=0 \cdot 006)$ or severe exacerbations requiring emergency department visit or hospital admission $(\mathrm{p}=0.013)$ were both significantly different.

Patients were stratified by previous asthma label or inhaled corticosteroid use and examined for interaction with high eosinophil counts (blood eosinophils $\geq 200$ cells per $\mu \mathrm{L}$ or sputum eosinophils $\geq 1 \cdot 25 \%$ ) in terms of lung function and exacerbations. No significant interactions were seen (appendix pp 18-19).

Patients who did not have acceptable sputum slides $(n=1498)$ were stratified by blood eosinophil counts to establish whether these patients had a phenotype with different characteristics (appendix p 20). Of these patients, the high eosinophil group had a slightly higher proportion of patients who used inhaled corticosteroids, had worse lung function, and had GOLD stages 3 and 4 than the low count group, as would be expected in these patients who were ineligible for sputum induction, but otherwise resembled the larger cohort of smokers.

Another stratification examined whether the blood eosinophil groups showed differences when restricted to just the 811 patients who were also in the sputum cohort (appendix p 21). Compared with the whole-cohort proportions, the sputum cohort had slightly greater proportions of current smokers (low blood eosinophil group $47 \%$ and high group $42 \%$ in sputum subcohort vs low group $42 \%$ and high group $37 \%$ in whole cohort), less inhaled corticosteroid use (low group 26\% and high group $31 \%$ vs low group $32 \%$ and high group $38 \%$ ), and slightly better lung function, but did not show the same radiological, clinical, or exacerbation differences observed for sputum eosinophil stratification (table 1; appendix p 21).

We examined whether the associations with worse lung function and quality of life, and greater exacerbations, emphysema, and air trapping in the high sputum eosinophil group were associated with increased sputum neutrophils as well as eosinophils. No difference in mean sputum neutrophil percentage between the high and low sputum eosinophil groups was seen $(\mathrm{p}=0 \cdot 12$; appendix $\mathrm{p}$ 11). Stratification of the sputum cohort into four groups of less than $1.25 \%$ or $1.25 \%$ or more eosinophils plus less than $68 \%$ or $68 \%$ or more neutrophils (on the basis of the mean sputum neutrophils of $68 \%$ [SD 21]), confirmed differences across low and high sputum eosinophil groups but did not show significant post-hoc differences between the high eosinophil plus high neutrophil and high eosinophil plus low neutrophil subgroups (appendix p 22).

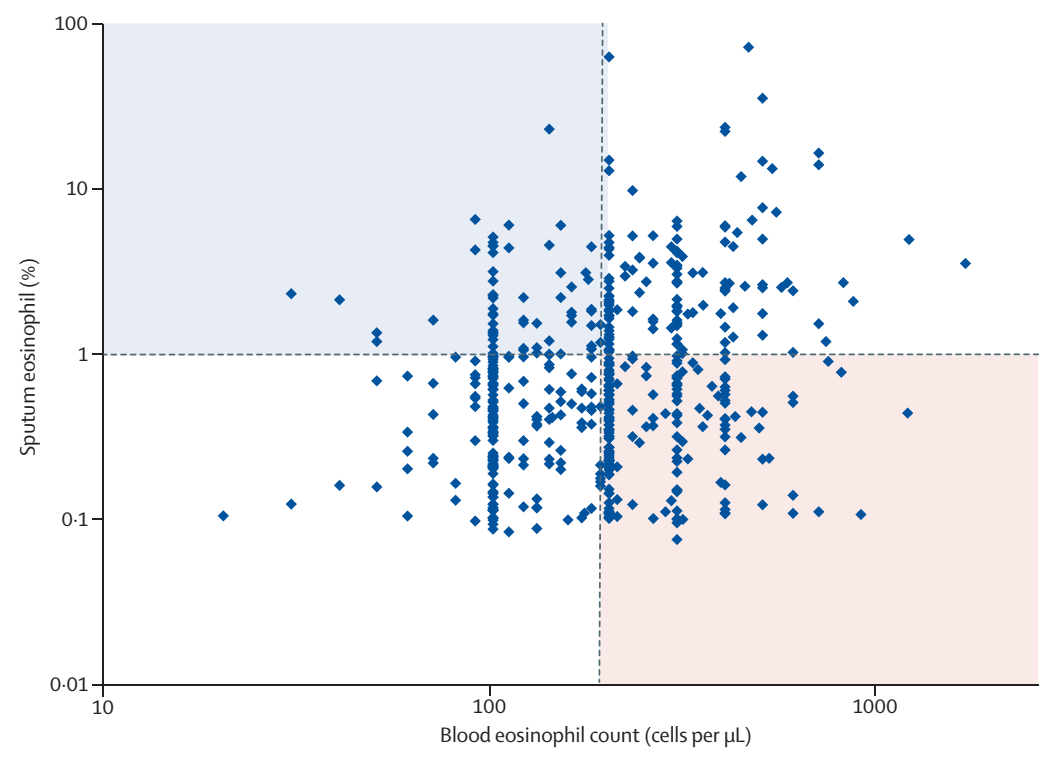

Figure 3: Distribution of blood eosinophils with respect to sputum eosinophils

Although a significant association between blood and sputum eosinophils was seen (Pearson correlation coefficient $r=0.178, p<0.0001$ ), use of the cutoff of 200 cells per $\mu \mathrm{L}$ blood or more eosinophils (vertical red line) to predict sputum eosinophils of at least $1.25 \%$ (horizontal red line) will mistakenly identify many patients with lower sputum eosinophil percentages (lower right quadrant, pink) and miss many patients with actual sputum eosinophils of $1.25 \%$ or more (upper left quadrant, blue) 


\begin{tabular}{|c|c|c|c|c|c|}
\hline & $\begin{array}{l}\text { Sputum }<1 \cdot 25 \% \text { and } \\
\text { blood }<200 \text { cells per } \mu \mathrm{L} \\
(n=355)\end{array}$ & $\begin{array}{l}\text { Sputum }<1 \cdot 25 \% \text { and } \\
\text { blood } \geq 200 \text { cells per } \mu \mathrm{L} \\
(n=290)\end{array}$ & $\begin{array}{l}\text { Sputum } \geq 1 \cdot 25 \% \text { and } \\
\text { blood }<200 \text { cells per } \mu \mathrm{L} \\
(n=50)\end{array}$ & $\begin{array}{l}\text { Sputum } \geq 1 \cdot 25 \% \text { and } \\
\text { blood } \geq 200 \text { cells per } \mu \mathrm{L} \\
(n=116)\end{array}$ & p value* \\
\hline \multicolumn{6}{|c|}{ Lung function before bronchodilator } \\
\hline $\mathrm{FEV}_{1}$ percentage predicted & $77(62-91)$ & $74(57-89)$ & $62(51-81)$ & $66(50-79)$ & $<0.0001$ \\
\hline FVC percentage predicted & $93(81-101)$ & $88(77-100)$ & 89 (76-99) & $87(76-96)$ & 0.033 \\
\hline $\mathrm{FEV}_{1}: \mathrm{FVC}$ & $0.67(0.58-0.74)$ & $0.66+(0.57-0.73)$ & $0.61+(0.47-0.66)$ & $0.61(0.52-0.69)$ & $<0.0001$ \\
\hline \multicolumn{6}{|c|}{ Lung function after bronchodilator } \\
\hline $\mathrm{FEV}_{1}$ percentage predicted & $84(70-97)$ & $81(66-95)$ & $76(63-87)$ & $77(63-90)$ & 0.005 \\
\hline FVC percentage predicted & $96(86-106)$ & $93(84-104)$ & $98(88-104)$ & $93(85-104)$ & $0 \cdot 24$ \\
\hline $\mathrm{FEV}_{1}: \mathrm{FVC}$ & $0.69(0.59-0.77)$ & $0.67+(0.59-0.76)$ & $0.63+(0.49-0.72)$ & $0.64(0.58-0.70)$ & 0.0004 \\
\hline Percentage reversibility & $7 \cdot 8(3 \cdot 6-15 \cdot 3)$ & $8 \cdot 5+(4 \cdot 0-16 \cdot 6)$ & $14 \cdot 5+(6 \cdot 8-22 \cdot 6)$ & $11 \cdot 4(5 \cdot 8-20 \cdot 5)$ & 0.0003 \\
\hline \multicolumn{6}{|l|}{ Exacerbations } \\
\hline Total exacerbations & $76(21 \%)$ & $47(16 \%)$ & $10(20 \%)$ & $32(28 \%)$ & 0.07 \\
\hline Requiring health-care use & $74(21 \%)$ & $45(16 \%)$ & $9(18 \%)$ & $31(27 \%)$ & 0.07 \\
\hline Antibiotics treatment & $56(16 \%)$ & $36(12 \%)$ & $10(20 \%)$ & $23(20 \%)$ & $0 \cdot 21$ \\
\hline Corticosteroid treatment & $37(10 \%)$ & $25(9 \%)$ & $6(12 \%)$ & $24(21 \%)$ & 0.006 \\
\hline Any drug treatment & $61(17 \%)$ & $38(13 \%)$ & $10(20 \%)$ & $27(23 \%)$ & 0.08 \\
\hline Severe & $35(10 \%)$ & $15(5 \%)$ & $3(6 \%)$ & $17(15 \%)$ & 0.013 \\
\hline
\end{tabular}

Data are median (IQR) or $\mathrm{n}(\%)$. p values are for comparisons of all four groups; for variables with significant values, post-hoc pairwise comparisons (Dunn's method) were done ( $p$ values not shown). *Kruskal-Wallis for continuous variables, $\chi^{2}$ for exacerbation categories. †High sputum eosinophils plus low blood eosinophils was significantly different from low sputum eosinophils plus high blood eosinophils by post-hoc Dunn's test. ‡Exacerbations involving a trip to an emergency department or admission to hospital.

Table 6: Lung function and exacerbations for patients in groups stratified by sputum and blood eosinophil counts

\section{Discussion}

This study in patients from the SPIROMICS cohort, who were smokers with COPD of varying severity as defined by GOLD stages, confirms that high concentrations of sputum eosinophils, but not blood eosinophils (unless in combination with high sputum eosinophils), identify a subset of patients with COPD with more severe airflow obstruction, worse quality of life, greater emphysema and air trapping, and greater number of exacerbations. Using sputum eosinophil stratification with cutoffs at either the mean $(1 \cdot 25 \%)$ or $2 \%$, we found significant associations of high sputum eosinophil counts with numbers of COPD exacerbations, including those that are severe and those requiring corticosteroid therapy. Additionally, significant associations were seen between sputum eosinophil concentration and lung function, before and after bronchodilation, including increased bronchodilator reversibility, respiratory symptoms, emphysema and air trapping assessed by QCT, and COPD severity by GOLD stage. By contrast, blood eosinophils alone, with cutoffs at 200 cells per $\mu \mathrm{L}$ or 300 cells per $\mu \mathrm{L}$, showed no association with COPD exacerbations, and associations with other phenotypic markers were small or non-significant. Although SGRQ symptom scores were associated with high eosinophil counts in both blood and sputum, the differences between groups for this variable was greater with the sputum stratification. Furthermore, no difference in CAT scores was seen with either blood or sputum stratification, which diminishes the validity of use of this score.
Notably, although the relationship between blood and sputum eosinophil counts was statistically significant, blood eosinophils did not reliably predict sputum eosinophils, showing a 72-74\% false-discovery rate and a $50 \%$ false-negative rate for sputum eosinophils of $2 \%$ or more. Lung function data stratified by high and low sputum and blood eosinophils showed no relationship with high blood eosinophils unless combined with high sputum eosinophils, whereas high sputum eosinophil count, regardless of blood eosinophil count, was associated with worse lung function. However, patients with COPD who had both high sputum and high blood eosinophil concentrations had both decreased lung function and more frequent exacerbations. These findings in a large multicentre cohort of smokers with a specified range of COPD severity have important implications for the proposed use of blood eosinophils alone as a predictive biomarker to guide individualised COPD therapies.

Our results extend observations from previous studies in COPD cohorts, including ECLIPSE, ${ }^{1}$ which focused primarily on neutrophilic airways inflammation, and, although reporting eosinophil presence, ${ }^{5}$ did not address the association of eosinophil counts with indices of COPD severity. ${ }^{45}$ The importance of our findings and of Th2 inflammation in COPD are emphasised by the recent report of Th2 gene expression overlap in airway epithelial samples from asthma and COPD cohorts, ${ }^{8}$ and by the shared clinical and biological characteristics between asthma and COPD that have been reported in 
several studies. ${ }^{5,7,1,27,28}$ However, differences should be noted between the SPIROMICS cohort and other COPD cohorts. The COPDGene study ${ }^{29}$ enrolled a larger cohort of 10000 patients who had an older minimum age (45 years) and a lower minimum smoking history ( $>10$ pack-years) than the SPIROMICS cohort, but phenotyping with induced sputum was not done. Sputum was also unavailable in the Copenhagen general population study, ${ }^{20}$ WISDOM ${ }^{21}$ INSPIRE, and TRISTAN. ${ }^{30}$ Although these studies reported exacerbations associated with high blood eosinophils, the entry requirements included past history of COPD exacerbations, which can affect the results because a past history of exacerbation is the most important factor in predicting future exacerbations. ${ }^{18}$

Emphasis on persistent Th2 inflammation in COPD has focused on eosinophils as predictors of exacerbations. Bafadhel and colleagues ${ }^{6}$ reported a cluster analysis using blood and sputum biomarkers, and peripheral blood eosinophils predicted sputum eosinophilassociated exacerbations of COPD. Sputum and peripheral blood eosinophils have been used to direct corticosteroid treatment and reduce occurrence of COPD

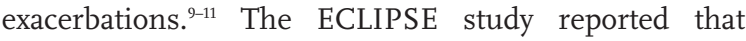
1483 patients stratified by blood eosinophil counts did not have different numbers of COPD exacerbations in the previous year. ${ }^{5}$ We confirm that h igher b lood eosinophils are not associated with COPD exacerbations except when combined with increased sputum eosinophils or with other characteristics, such as a previous history of exacerbation. ${ }^{18}$ However, we established that in the SPIROMICS cohort, higher sputum eosinophil counts alone are associated with exacerbations even in mild to moderate COPD.

Eosinophil counts have been suggested to indicate the response to corticosteroids, anti-interleukin-5, or antiinterleukin-5 receptor therapy. ${ }^{9-12,32}$ In a retrospective analysis of two COPD exacerbation studies with longacting $\beta$ agonists and inhaled corticosteroids, Pascoe and colleagues $^{33}$ showed that patients with high blood eosinophil counts had greater reductions in COPD exacerbations than those with low blood eosinophil counts. These observations suggest that eosinophils might be important in development of COPD exacerbations or as a potential biomarker of some COPD exacerbations. However, two factors might have influenced $\mathrm{p}$ revious observations that associated high blood eosinophil counts with greater numbers of COPD exacerbations: selection criteria requiring recent exacerbation and perhaps worse lung function are both related to future COPD exacerbations and might be surrogate markers of increased sputum eosinophils. Increased blood eosinophils, if also combined with increased sputum eosinophils, were associated with COPD exacerbations in our results in the SPIROMICS cohort. However, blood eosinophils alone were not associated with exacerbations, even when the patient had a previous asthma label. This observation contrasts with the association of blood eosinophil count of 275 cells per $\mu \mathrm{L}$ or more with all-cause mortality in 662 patients in a previous study; ${ }^{34}$ however, that study found no change after exclusion of patients with asthma.

We also examined other characteristics in the blood and sputum eosinophil subgroups of SPIROMICS patients that might suggest overlap with asthma: bronchodilator reversibility, IgE concentrations, and previous asthma label. High blood eosinophil counts with two different cutoffs ( $\geq 200$ or $\geq 300$ cells per $\mu \mathrm{L}$ ) did not have greater acute bronchodilator reversibility, whereas increased sputum eosinophils groups did show significantly greater reversibility. IgE concentrations were significantly higher in the high versus low blood eosinophil groups, but no difference was seen between the sputum groups. However, the IgE concentrations in the SPIROMICS blood and sputum eosinophil subgroups were well below the median ( 91 IU per $\mathrm{mL}$ ) and high (173 IU per $\mathrm{mL}$ ) IgE cutoffs reported in a study of asthma-COPD overlap syndrome. ${ }^{35}$ Only grouping by $2 \%$ or more sputum eosinophils showed differences in proportions of patients who reported previous asthma label; but the proportion reporting asthma was still small (12. $5 \%$ of the $\geq 2 \%$ group).

A higher proportion of patients had been prescribed inhaled corticosteroids in the high blood and sputum eosinophil groups than in the low eosinophil groups. This observation was made despite an expected reduction in eosinophil concentrations with corticosteroid therapy. Use of corticosteroids in the higher eosinophil groups potentially reflects individuals who are more likely to have had exacerbations, consistent with GOLD guideline recommendations for corticosteroids in patients with COPD who have frequent exacerbations. ${ }^{13}$

Limitations of this report include somewhat milder COPD in the group who were able to successfully induce sputum. For safety reasons, SPIROMICS patients with post-bronchodilator $\mathrm{FEV}_{1}$ percentage predicted less than $35 \%$ did not have sputum induction, limiting the sputum subgroup to patients with GOLD stages $0-3$. Although our cohorts (both for blood and sputum eosinophil analyses) included patients who smoked and had at least 20 packyears but had GOLD stage 0 (ie, had preserved lung function so did not meet the criteria for COPD diagnosis), these patients were included because they have been shown to have symptoms, exacerbations, activity limitations, and radiological evidence of airway disease consistent with early COPD. ${ }^{36}$ Although SPIROMICS exacerbations data were retrospective, validity of retrospective data for future risk of COPD exacerbation has been shown in the ECLIPSE study, in which selfreported exacerbations from the previous year had predicted exacerbations during the first year of follow-up more accurately than all other variables examined. ${ }^{18}$ An additional limitation, at least in clinical settings, is the difficulty of accurate sputum analysis. Even in the SPIROMICS network with centralised training for 
sputum induction and processing, some factors still prevented sputum analysis on all eligible patients (appendix pp 2-5). However, analysis of those who did not have sputum analysis stratified by blood eosinophil concentrations did not differ substantially from the larger cohort who did have sputum samples taken.

Of interest, longitudinal follow-up of the SPIROMICS cohort might be used to confirm the observations of Hospers and colleagues, ${ }^{34}$ that peripheral eosinophils are associated with all-cause mortality over a period of 30 years. Alternatively, the differences in lung function associated with blood eosinophil counts (cutoff 2\%) observed in the much smaller study over 9 years by Rogliani and colleagues ${ }^{37}$ should be examined in the larger SPIROMICS cohort longitudinally.

In summary, using the large and comprehensive phenotypic characterisation of the SPIROMICS cohort, we show that stratification by increased sputum eosinophil inflammation identified a subgroup with more severe COPD, decreased lung function, worse emphysema and air trapping, and more COPD exacerbations. Peripheral blood eosinophil counts identified a subgroup with decreased lung function without other indices of more severe COPD, specifically exacerbations, unless examined on the background of increased sputum eosinophils. Furthermore, blood eosinophil counts did not accurately predict sputum eosinophil counts. These observations confirm the importance of assessing eosinophils in the airways. In future, patients with high sputum eosinophil concentrations should be followed longitudinally to establish whether this factor has long-term effects on the progression of COPD.

\section{Contributors}

ATH, FJM, JLC, CBC, CMD, NNH, RGB, EAH, REK, EK, WKO'N, SPP, PGW, MKH, and ERB contributed to the concept and design of the study. ATH, FJM, JLC, CMD, NNH, SC, NP, VEO, RGB, EEC, DJC, CBC, EAH, REK, EK, RP, NEA, PGW, MKH, DAM, and ERB recruited the cohort and acquired the data. ATH, FJM, JLC, NNH, NP, XL, RGB, EEC, CBC, DJC, EAH, RP, PGW, MKH, DAM, and ERB analysed and interpreted the data. All authors drafted and critically revised the manuscript, approved the final version for publication, and agreed to be accountable, ensuring the accuracy and integrity of the work.

\section{Declaration of interests}

ATH, CMD, and DAM report support from the National Heart, Lung, and Blood Institute (NHLBI) and the Foundation for the National Institutes of Health (FNIH) during conduct of study. FJM reports grants from NIH; personal fees from Forest, Janssens, GlaxoSmithKline (GSK), Nycomed/ Takeda, Amgen, AstraZeneca, Boehringer Ingelheim, Ikaria/Bellerophon, Genentech, Novartix, Pearl, Pfizer, Roche, Sunovion, Theravance, Axon, CME Incite, California Society for Allergy and Immunology, Annenberg, Informa, Integritas, InThought, Miller Medical, National Association for Continuing Education, Paradigm, Peer Voice, UpToDate, Haymarket Communications, Western Society of Allergy and Immunology, Unity Biotechnology, ConCert, Lucid, Methodist Hospital, Prime, and WebMD. JLC reports grants from NHLBI, National Institute of Allergy and Infectious Disease of the National Institute of Health, the Department of Veterans Affairs, FNIH, and the COPD Foundation. NNH reports grants from AstraZeneca, NIH, the COPD Foundation, Boehringer Ingelheim, and GSK. SC reports grants from MedImmune; personal fees from AstraZeneca; and non-financial support from Genentech. FJM reports grants from NIH; personal fees from Forest, Janssens, GSK, Nycomed/
Takeda, Amgen, AstraZeneca, Boehringer Ingelheim, Ikaria/Bellerophon, Genentech, Novartix, Pearl, Pfizer, Roche, Sunovion, Theravance, Axon, CME Incite, California Society for Allergy and Immunology, Annenberg, Informa, Integritas, InThought, Miller Medical, National Association for Continuing Education, Paradigm, Peer Voice, UpToDate, Haymarket Communications, Western Society of Allergy and Immunology, Unity Biotechnology, ConCert, Lucid, Methodist Hospital, Prime, and WebMD. VEO reports personal fees from CSL Behring. RGB reports grants from NIH, FNIH, and the COPD Foundation; grants from Alpha1 Foundation; and personal fees from UpToDate. EEC reports support from NHLBI, FNIH, Genentech, and the COPD Foundation during conduct of study. DJC reports support from NHLBI and the COPD Foundation. CBC reports grants from Equinox Health Clubs, Amgen, and Spiration; personal fees from Equinox Health Clubs, PulmonX, Boehringer Ingelheim, GSK, and SPIRATION; and part-time work for scientific engagement for GSK Global Respiratory Franchise outside of submitted work. EAH is a founder and shareholder of VIDA Diagnostics, a company commercialising lung image analysis software developed, in part, at the University of Iowa. EK reports grants from the NIH and the FNIH; nonfinancial support (inhalers for spirometry testing) from Boehringer Ingelheim and GSK during the conduct of the study; and grants from Boehringer Ingelheim, Novartis, Pearl/AstraZeneca, and Sunovion/ Sepracor. RP reports support from NHLBI and the COPD Foundation; and a grant from the Department of Veterans Affairs. MKH reports support from NIH, FNIH, and the COPD Foundation; consulting fees from GSK, Boehringer Ingelheim, Novartis, AstraZeneca, and Sunovion; and royalties from UptoDate. SPP reports grants from NIH, NHLBI, and the COPD Foundation. PGW reports grants from Medimmune; personal fees from Genentech/Roche, AstraZeneca, Novartis, Neostem, and Janssen; and a patent for Asthma diagnostics pending. All other authors declare no competing interests.

\section{Acknowledgments}

SPIROMICS was supported by contracts from the NIH/NHLBI (HHSN268200900013C, HHSN268200900014C, HHSN268200900015C, HHSN268200900016C, HHSN268200900017C, HHSN268200900018C HHSN268200900019C, HHSN268200900020C), which were supplemented by contributions made through the FNIH from AstraZeneca; Bellerophon Therapeutics; Boehringer Ingelheim Pharmaceuticals; Chiesi Farmaceutici; Forest Research Institute; GSK; Grifols Therapeutics; Ikaria; Nycomed; Takeda Pharmaceutical Company; Novartis Pharmaceuticals Corporation; Regeneron Pharmaceuticals; Sanofi, and the COPD Foundation. Additional CT analyses were made possible by NIH/NHLBI HL122438. We thank the SPIROMICS participants and participating physicians, investigators, and staff for making this research possible. We would like to acknowledge the following current and former investigators of the SPIROMICS sites and reading centres: Wayne $\mathrm{H}$ Anderson, Russell $\mathrm{P}$ Bowler,

Alejandro P Comellas, Gerard J Criner, Ronald G Crystal, Mark T Dransfield, Christine M Freeman, Robert J Kaner, Jerry A Krishnan, Stephen C Lazarus, John D Newell Jr, Elizabeth C Oelsner, Stephen I Rennard, Donald P Tashkin, Mary Beth Scholand, J Michael Wells, and Robert A Wise.

References

1 Singh D, Edwards L, Tal-Singer R, Rennard S. Sputum neutrophils as a biomarker in COPD: findings from the ECLIPSE study. Respir Res 2010; 11: 77-89.

2 Hiemstra PS. Altered macrophage function in chronic obstructive pulmonary disease. Ann Am Thorac Soc 2013; 10 (suppl): S180-85.

3 Chung KF. Cytokines in chronic obstructive pulmonary disease. Eur Respir J Suppl 2001; 34: 50s-59s.

4 Sethi S, Mahler DA, Marcus P, Owen CA, Yawn B, Rennard S. Inflammation in COPD: implications for management. Am J Med 2012; 125: 1162-70

5 Singh D, Kolsum U, Brightling CE, et al. Eosinophilic inflammation in COPD: prevalence and clinical characteristics. Eur Respir J 2014; 44: 1697-700.

6 Bafadhel M, McKenna S, Terry S, et al. Acute exacerbations of chronic obstructive pulmonary disease; identification of biologic clusters and their biomarkers. Am J Respir Crit Care Med 2011; 184: 662-71. 
7 Hardin M, Silverman EK, Barr RG, et al. The clinical features of the overlap between COPD and asthma. Respir Res 2011; 12: 127.

8 Christenson SA, Steiling K, van den Berge M, et al. Asthma-COPD overlap: clinical relevance of genomic signatures of type 2 inflammation in chronic obstructive pulmonary disease. Am J Respir Crit Care Med 2015; 191: 758-66.

9 Brightling CE, Monteiro W, Ward R, et al. Sputum eosinophilia and short-term response to prednisolone in chronic obstructive pulmonary disease: a randomized controlled trial. Lancet 2000; 356: 1480-85.

10 Siva R, Green RH, Brightling CE, et al. Eosinophilic airway inflammation and exacerbations of COPD: a randomized controlled trial. Eur Respir J 2007; 29: 906-13.

11 Bafadhel M, McKenna S, Terry S, et al. Blood eosinophils to direct corticosteroid treatment of exacerbations of chronic obstructive pulmonary disease, a randomized placebo-controlled trial. Am J Respir Crit Care Med 2012; 186: 48-55.

12 Brightling CE, Bleecker ER, Panettieri RA Jr, et al. Benralizumab for chronic obstructive pulmonary disease and sputum eosinophilia: a randomized, double-blind, placebo-controlled phase 2a study. Lancet Respir Med 2014; 2: 891-901.

13 Global Strategy for the Diagnosis, Management, and Prevention of COPD. Global Initiative for Chronic Obstructive Lung Disease (GOLD), 2017. http://goldcopd.org/gold-2017-global-strategy diagnosis-management-prevention-copd/ (accessed Nov 16, 2016).

14 Negewo NA, McDonald VM, Baines KJ, et al. Peripheral blood eosinophils: a surrogate marker for airway eosinophilia in stable COPD. Int J Chron Obstruct Pulmon Dis 2016; 11: 1495-504.

15 Hastie AT, Moore WC, Li H, et al. Biomarker surrogates do not accurately predict sputum eosinophil and neutrophil percentages in asthmatic subjects. J Allergy Clin Immunol 2013; 132: 72-80.

16 Mukherjee M, Nair P. Blood or sputum eosinophils to guide asthma therapy? Lancet Respir Med 2015; 3: 824-25.

17 Ghebre MA, Bafadhel M, Desai D, et al. Biological clustering supports both "Dutch" and "British" hypotheses of asthma and chronic obstructive pulmonary disease. J Allergy Clin Immunol 2015; 135: 63-72.

18 Hurst JR, Vestbo J, Anzueto A, et al. Susceptibility to exacerbation in chronic obstructive pulmonary disease. N Engl J Med 2010; 363: $1128-38$.

19 Siddiqui SH, Guasconi A, Vestbo J, et al. Blood eosinophils: a biomarker of response to extrafine beclomethasone/formoterol in chronic obstructive pulmonary disease. Am J Respir Crit Care Med 2015; 192: 523-25.

20 Vedel-Krogh S, Nielsen SF, Lange P, Vestbo J, Nordestgaard BG. Blood eosinophils and exacerbations in COPD: the Copenhagen general population study. Am J Respir Crit Care Med 2016; 193: 965-74.

21 Watz H, Tetzlaff K, Wouters EF, et al. Blood eosinophil count and exacerbations in severe chronic obstructive pulmonary disease after withdrawal of inhaled corticosteroids: a post-hoc analysis of the WISDOM trial. Lancet Respir Med 2016; 4: 390-98.

22 Couper D, LaVange LM, Han M, et al. Design of the Subpopulations and Intermediate Outcomes in COPD Study (SPIROMICS). Thorax 2014; 69: 491-94.
23 Hastie AT, Alexis NE, Doerschuk C, et al. Blood eosinophils poorly correlate with sputum eosinophils, and have few associations with spirometry, clinical and quantitated computed tomography measures compared to sputum eosinophils in the SPIROMICS cohort. Am J Respir Crit Care Med 2016; A6168 (abstr).

24 Sieren JP, Newell JD Jr, Barr RG, et al. SPIROMICS protocol for multicenter quantitative computed tomography to phenotype the lungs. Am J Respir Crit Care Med 2016; 194: 794-806.

25 Boes JL, Hoff BA, Bule M, et al. Parametric response mapping monitors temporal changes on lung CT scans in the Subpopulations and Intermediate Outcomes Measures in COPD Study (SPIROMICS). Acad Radiol 2015; 22: 186-94.

26 Ott RL, Longnecker MT. An introduction to statistical methods and data analysis, 7th edn. Boston: Brooks/Cole, 2015.

27 Carolan BJ, Sutherland ER. Clinical phenotypes of chronic obstructive pulmonary disease and asthma: recent advances. J Allergy Clin Immunol 2013; 131: 627-34.

28 Postma DS, Rabe KF. The asthma-COPD overlap syndrome. N Engl J Med 2015; 373: 1241-49.

29 Regan EA, Hokanson JE, Murphy JR, et al. Genetic epidemiology of COPD (COPDGene) study design. COPD 2010; 7: 32-43.

30 Pavord ID, Lettis S, Locantore N, et al. Blood eosinophils and inhaled corticosteroid/long-acting $\beta$ - 2 agonist efficacy in COPD Thorax 2015; 71: 118-25.

31 Bafadhel M, Pavord ID, Russell REK. Eosinophils in COPD: just another biomarker? Lancet Respir Med 2017; 5: 747-59.

32 Dasgupta A, Kuarsgaard M, Capaldi D, et al. A pilot randomized clinical trial of mepolizumab in COPD with eosinophilic bronchitis. Eur Respir J 2017; 49: 1602486.

33 Pascoe S, Locantore N, Dransfield MT, Barnes NC, Pavord ID. Blood eosinophil counts, exacerbations, and response to the addition of inhaled fluticasone furoate to vilanterol in patients with chronic obstructive pulmonary disease: a secondary analysis of data from two parallel randomized controlled trials. Lancet Respir Med 2015; 3: 435-42.

34 Hospers JJ, Schouten JP, Weiss ST, Postma DS, Rijcken G. Eosinophilia is associated with increased all-cause mortality after a follow-up of 30 years in a general population sample. Epidemiology 2000; 11: 261-68.

35 Tamada T, Sugiura H, Takahashi T, et al. Biomarker-based detection of asthma-COPD overlap syndrome in COPD populations. Int J Chron Obstruct Pulmon Dis 2015; 10: 2169-76.

36 Woodruff PG, Barr RG, Bleecker ER, et al. Clinical significance of symptoms in smokers with preserved pulmonary function. N Engl J Med 2016; 374: 1811-21.

37 Rogliani P, Puxeddu E, Ciaprini C, et al. The time course of pulmonary function tests in COPD patients with different levels of blood eosinophils. BioMed Res Int 2016; 2016: 4547953. 